\title{
Factors Influence Malaysian Small-Medium Enterprise to Engage in Facebook Marketing
}

Lee Borway, Adriana Mohd. Rizal, Haliyana Khalid, Zarina Abdul Salam and Musli Sahimi

To Link this Article: http://dx.doi.org/10.6007/IJARBSS/v11-i11/11266

DOI:10.6007/IJARBSS/v11-i11/11266

Received: 06 September 2021, Revised: 25 September 2021, Accepted: 17 October 2021

Published Online: 09 November 2021

In-Text Citation: (Borway et al., 2021)

To Cite this Article: Borway, L., Rizal, A. M., Khalid, H., Salam, Z. A., \& Sahimi, M. (2021). Factors Influence Malaysian Small-Medium Enterprise to Engage in Facebook Marketing. International Journal of Academic Research in Business and Social Sciences, 11(11), 686 - 695.

\section{Copyright: (c) 2021 The Author(s)}

Published by Human Resource Management Academic Research Society (www.hrmars.com)

This article is published under the Creative Commons Attribution (CC BY 4.0) license. Anyone may reproduce, distribute, translate and create derivative works of this article (for both commercial and non-commercial purposes), subject to full attribution to the original publication and authors. The full terms of this license may be seen at: http://creativecommons.org/licences/by/4.0/legalcode

Vol. 11, No. 11, 2021, Pg. $686-695$

Full Terms \& Conditions of access and use can be found at http://hrmars.com/index.php/pages/detail/publication-ethics 


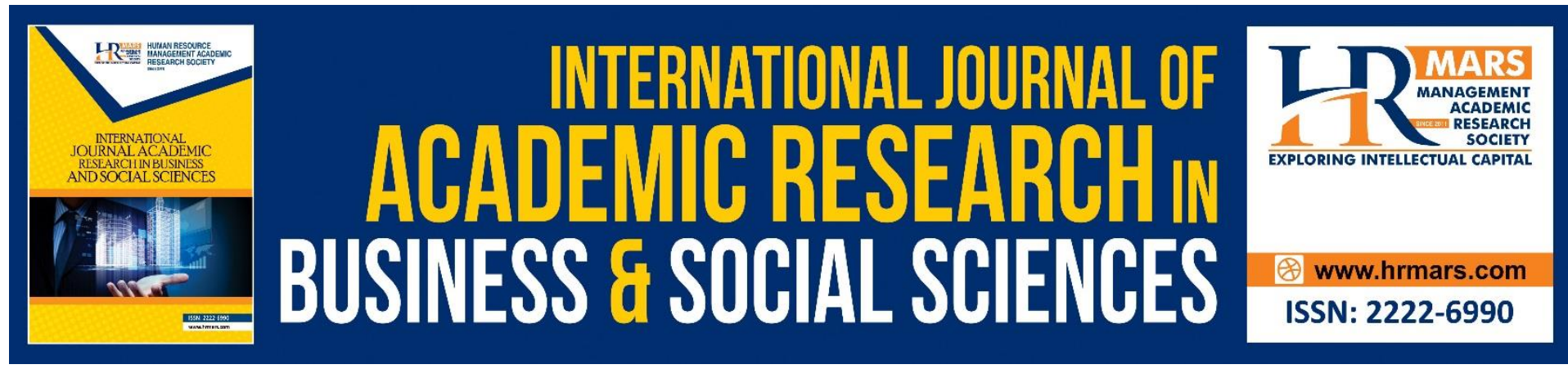

\title{
Factors Influence Malaysian Small-Medium Enterprise to Engage in Facebook Marketing
}

\author{
Lee Borway ${ }^{1}$, Adriana Mohd. Rizal ${ }^{2}$, Haliyana Khalid ${ }^{3}$, Zarina \\ Abdul Salam ${ }^{4}$ and Musli Sahimi ${ }^{5}$ \\ ${ }^{1,2,3,4}$ Azman Hashim International Business School, Universiti Teknologi Malaysia, Malaysia, \\ 2,3 University of Business and Technology, Jeddah, Saudi Arabia, ${ }^{5}$ Graduate School of \\ Business, Universiti Kebangsaan Malaysia, Malaysia
}

\begin{abstract}
Social media plays an important role as a marketing tool to promote Small and Medium Enterprises (SMEs') businesses. Among the social media platforms, Facebook is the preferred advertisement tool for SMEs. It is because Facebook provides more features for SMEs to communicate with their customers such as by using direct messenger, comments, like, and share. SMEs engage in social media to lower the cost of advertisements, attract new customers through online contact, improve the interaction with customers or customer engagement, and create brand awareness of the company. Most of the past research has focused on the value of brand awareness and customer engagement on Facebook, however, there is a limited amount of research related to the value of cost-efficiency and attracting a new customer base especially in a developing country like Malaysia. As such, this study reviews the literature on social media marketing and factors influencing Malaysian SMEs to engage in Facebook online marketing. This study also proposes a conceptual framework on the factors influencing Malaysian SMEs to engage in Facebook online marketing.
\end{abstract}

Keywords: Facebook Marketing, Brand Awareness, New Customer Base, Cost Efficiency, and Customer Engagement

\section{Introduction}

Malaysia is a country that encourages entrepreneurship. By the end 2019, a total number of 1,344,911 companies and 7,511,278 businesses were registered under the Companies Commission of Malaysia (Companies Commission of Malaysia, 2020). Part of these figures represents the establishment of Small-Medium Enterprises (SMEs) in Malaysia as well. Due to many SMEs established in the market, this creates a greater challenge for SMEs to gain a strong market share.

In the 21st century, the younger generation has more knowledge and engagement on the internet and technological platforms of digitalised environment than the older generations (Das and Sankar, 2016). Digital marketing is defined as a promotional tool that is deployed to reach potential customers through digital technologies. Digital marketing enhances the promotion of products, services, or company brand through one or more forms of digital media. Due to these benefits, SMEs can easily promote the profile of a company from three 
electronic platforms, namely internet searching, social media, and mobile phone apps (Das and Sankar, 2016).

Social media marketing is defined as a marketing tool using any form of Internet media for marketing purposes (Mabry and Porter, 2010). Among the social media platforms, most SMEs prefer to use Facebook as an advertisement tool (Wee et. al., 2020) to attract new customers and generate sales revenue (Mital and Sarkar, 2011). With many Facebook fans, SMEs can create an impression and create value for customers. The information on the organic and reach of the advertisements leads to a better decision on cost spending on such advertisements (Mital and Sarkar, 2011). The customers who are willing to give a "Like" on the Facebook page or respond to an advertisement are more likely to have interest in the brand. This improves the open interaction between customers and business owners (Terry and Savitz, 2011). SMEs engage in social media to lower the cost of advertisements (Wee et. al. 2020), attract new customers through online contact as well as improve the interaction with customers and the branding of the company (Ohajionu and Soney, 2015).

Social media marketing has created many opportunities and challenges for SMEs to implement effective advertisements and promotions (Leung, 2012). As SMEs engaging in one or more social media platforms to improve their marketing communication, attention is being paid to its effectiveness. Although social media claim that it improves SMEs' marketing activities, there is only limited research to support such claims (Bower, 2012). Leung (2012) stated that social media marketing has different sets of approaches in terms of the design and outline of an advertisement compared to the traditional method of advertising (newspapers, TV, radio, billboards, etc.).

Although SMEs have a strong understanding of the importance of social media marketing, most SMEs lack the knowledge and time to manage social media marketing effectively (Peaslee, 2015). Furthermore, most of the users of social media have difficulties in understanding the correct measurement (metrics) such as rate of impression, organic/paid reach, relevance score, pay-per-click, cost-per-post (Hosford, 2011). Other metrics such as cost efficiency, traffic-building, social buzz, brand development, customer comments, lead generation, and event promotion have a different format of measurement and definition (Hosford, 2011). SMEs may not engage the method and approach that are effective for their social media marketing.

There has been a significant increase in the number of SMEs engaging in social media marketing (Bank and Haan 2017; Leung 2012; Somera 2014). The main intention for SMEs to engage in social media marketing is to seek new opportunities and the expansion of business. Among those intentions, brand awareness, cost-efficiency, develop a new customer base, and customer engagement are mentioned the most in previous research. Sjoberg (2017) stated that the features of social media have been perceived as a great opportunity for companies to create brand awareness globally. However, it is challenging for SMEs due to a lack of knowledge to build effective brand awareness through social media.

The cost of advertisements has always been a challenge for SMEs to justify their effectiveness, especially on a social media platform. Leung (2012) stated that the determination of the effectiveness of social media has a different approach from traditional marketing. The metrics and measurements for traditional marketing may not apply to social media. Mickey (2011) stated that $61 \%$ of SMEs indicated that social media marketing is one of the top challenges to implement in a business strategy as it requires knowledge and skill to implement. Therefore, achieving cost-efficiency in social media marketing has become a great challenge to SMEs to sustain their businesses over the long run. 
Building a customer base from social media is another challenge for SMEs. Chin, Lu and Wu (2015) stated that social media allows SMEs to build a customer base through Facebook pages, subscriptions, and followers. The more "likes" and "shares" that a Facebook page receives, the more opportunities are available for a company to attract and engage with new customers and generate sales revenue from them. To receive more "likes" and "shares", the organisation needs to create value for customers (Somera, 2014). The interaction between customers and companies is another factor encouraging SMEs to engage in social media marketing. Gajewski (2013) stated that customer engagement through social media has become one of the main factors to build long-term relationships and attract new customers. Although social media provide convenience for SMEs to engage with their customers, there are challenges for them in retaining the value of the interaction, or else customers may leave bad comments, reviews, or negative feedback about the business.

The past research has focused on the value of brand awareness and customer engagement on Facebook. Inherently, a lack of study in the Malaysian business context would make it difficult for Malaysian SMEs to apply the knowledge to their business operation. Therefore, this research is needed to identify factors that influence SMEs to engage in Facebook online marketing in Malaysia.

\section{Literature Review \\ Social Media Platforms}

Schmidt and Ralph (2011) defined social media as the tools to connect people through online technology. Kaplan and Haenlein (2012) defined social media as the internet-based application with the foundation of Web 2.0 that allows the creation and exchange of usergenerated content. Schmidt and Ralph (2011) also state that social media can be categorised into four tools: social networks, blogs, microblogs, and real simple syndication. Kim (2010) identified that most of the social media have similar characteristics, it can be group into three general categories: social networking sites (Facebook, Twitter, MySpace, and LinkedIn), video sharing sites (YouTube), and micro-blogging (Blogger, Jaiku, or Pownce).

Facebook, Twitter, Pinterest, YouTube, and Instagram are the most popular social media platforms for customers and businesspeople (Banks and Haan, 2017). Social media platform provides opportunities for SMEs to build a network and create exposure to customers (Cox, 2012). In Malaysia, the definition of Small-Medium Enterprise (SME) covers all sectors, which are service line, manufacturing, agriculture, construction, and mining. The criteria of SME can be determined by sales turnover (less than RM300,000) or the number of full-time employees (less than 75 employees) to categorise the size of the company (SME Corp, 2013). The method of social media has changed the way of communication channels all around the world. It allows SMEs to build a connection with customers in the local and international markets.

Among the social media platforms, Facebook is the biggest social network worldwide with over 2.89 billion active monthly users as of second quarter of 2021 (Statista Research Department, 2021). Facebook users can post and share information, such as photographs, life activities, real-time thoughts, comments and conversations on the user's network or community. Due to Facebook's nature and features, the interaction between SMEs and customers can be enhanced. SMEs can take the opportunity to build brand awareness to attract a new base of customers.

Gregori and Baltar (2013) stated that more and more SMEs are using Facebook as a networking tool to build and market their products/services specifically to the younger generation. Due to the high level of usage of technological devices among younger 
generations, social media has become an essential tool for young customers. Social media provides platforms to SMEs to create brand awareness (Leung, 2012), especially to younger generations. Facebook features such as creating a community within the business create brand values and customer engagement that help reduce competition. Customer engagement helps SMEs highlight their product differentiation, vision, brand, and improve quality.

Because the number of populations in social media has increased, SMEs can maximise the effort to creating a strong brand in social media especially on Facebook. SMEs need to maintain the quality of products and services as customers can easily leave good or bad comments which would affect the company's reputation. As customers can strengthen brand perception or weaken it, SMEs need to take extra caution to safeguard their brands.

\section{Malaysia SMEs and Internet Users}

Malaysia Communication and Multimedia Commission (MCMC)'s Internet User Survey 2018 states that there are 28.7 million internet users in Malaysia. It has an increase of 10.5 percent internet users compared to 2016. Among social networking and communication application, there is a total number of $\mathbf{2 4 . 6}$ million social media users in Malaysia. Among those users, 97.3 percent owned a Facebook account. Facebook is the most preferred social media platform in the country, followed by Instagram (57.0 percent), YouTube (48.3 percent), Google+ (31.3 percent), Twitter (23.8 percent) and Linkedln (13.3 percent).

The internet user spent an average of 6.6 hours online per day. Interestingly, there is no significant difference between males and females spending time online. Male users spent an average of 6.7 hours per day, while female users spent an average of 6.6 hours per day (Internet User Survey, 2018). Among the technological devices to access the internet, smartphones remained the highest for internet tools to access the internet compared to a notebook, desktop computer, tablets and Smart Tv. Due to the increasing computing power of the smartphone, users can easily access the internet, which led to the decline in using the laptop, desktop, tablet, and smart TV (Internet User Survey, 2018).

For online activities, social engagement is the most frequent activity for internet users. There is 96.5 percent of users using the internet for messaging, 85.6 percent used the internet for social networking, 85.5 percent used the internet to get information, 77.6 percent used the internet to watch or download video and 61.9 percent used the internet for work-related (Internet User Survey, 2018).

The increasing number of internet users was due to the expansion of mobile broadband and competition between broadband operators. With huge investment in expanding the facilities and improving the quality of services, Malaysians can now easily subscribe to $3 \mathrm{G}$ and LTE networks for a minimal cost. Therefore, the accessibility of the internet creates a need for SMEs to engage in Facebook online marketing.

\section{Factors Influence SMEs to Engage in Facebook Marketing}

Facebook marketing studies mainly focus on its effectiveness (Leung, 2012; Somera, 2014; Banks and Haan, 2017) and benefits (Behan, 2013; Brown-Peterson, 2017). However, a study on the factors that influence Malaysian SMEs to engage in Facebook marketing is lacking.

Building a strong brand creates a long-term relationship with customers. Brand awareness plays an important role in fostering the relationship between SMEs and customers. Brand awareness is the ability to trace or node to a customer's memory which allows them to identify the brand in different kinds of conditions. It often provides an identity of the product 
by linking the brand with a product characteristic (Sjoberg, 2017). An identical brand helps to attract potential customers and create an understanding of which product belongs to a company. Brand awareness creates a significant impact that low brand awareness comes with low customer involvement and loyalty. Therefore, strong brand recognition creates an identity in the customers' minds (Haque, Momen, Sultana, and Yasmin, 2013). Haque, et al (2013) added that brand can be characterised as brand recognition and brand recall. Brand recognition allows customers to identify the brand while at the same time the brand also representing as a hint (Rios and Riquelme, 2010). While brand recall enables customers to recall a perception of an item (Rios and Riquelme, 2010). Brand recognition benefits customers when purchasing in the store; while brand recall benefits customers with certain product features. Haque et al. (2013) added that brand awareness requires visualization like logo and verbalization like a brand name. Unique advertising with special visualisation creates a strong image and thus, improves brand awareness. As such, brand awareness can influence SMEs to engage in Facebook marketing.

The Interactive Advertising Bureau (IAB) has published a research study on the benefits of Facebook for several businesses in 2012 (Brown-Peterson, 2017). Companies such as CocaCola, Disney, Converse, Starbucks, Red Bull, and Oreo are using Facebook's "like" features obtained over millions of Facebook fans. Because Facebook has many users, SMEs can easily attract a new customer base by getting more fans to support the company and brand. Facebook received USD 3,710 billion in advertisement revenue in 2011 (Deighton and Kornfeld, 2012). About 83 percent of companies are using Facebook as a marketing tool (Statista, 2018).

Somera (2014) added that customers that tend to engage with a brand are likely to make a monetary transaction. Somera (2014) further claims that customers who purchase products or services from an online company would lead to a strong online relationship. If the company putting more value on the customer, it builds a strong encouragement to customers to constantly visit and support the company's Facebook page. Chin, Lu and Wu (2015) identified that if a company's post or the page has a greater number of "Likes" from customers, the customer's families and friends have the potential to view the company's post or page. However, it is hard to define whether the number of "Likes" increases represents a strong relationship on contributing to the increase in sales revenue.

Dehghani and Turner (2015) state the effectiveness of the Facebook advertisement can be measured by the numbers of "Likes" and "Shares". The more "Likes" and "Shares" create a strong brand and influence customers to spend more money on a particular product or service. In addition, high numbers of "Likes" or "Shares" increases a good image of the company and later, increases the brand's trustworthiness and reliability to customers. As a result, Facebook marketing has the potential to create a new customer base for SMEs.

The definition of return on investment (ROI) is the measurement of performance appraising the effectiveness of an investment. The investor can calculate ROI by dividing the value of an investment and the cost of investment. The result is shown by percentage or ratio (Chen, 2019). Palmer and Koenig-Lewis (2009) state that it is challenging for SMEs to measure the effectiveness of Facebook marketing or its ROI. Fisher (2009) added that the metrics of ROI in traditional marketing are not applicable to determine the effectiveness of Facebook marketing. The ROI formula is not suitable to apply and elaborate on its effectiveness as the characteristics of all social media platforms are different (Fisher, 2009). Leung (2012) states that Facebook has been claimed to improve marketing activities. However, there is little research that supports the claim. Stelzner (2013) added that SMEs are looking for a solution 
to measure the ROI of Facebook marketing. Thus, it is essential to discover the component and elements of marketing performance to measure effectiveness. As such, cost efficiency plays a significant role in whether SMEs would engage in Facebook marketing.

Customer engagement is defined as an emotional connection between the company and customers (Farook and Abeysekara, 2015). SMEs who constantly build a relationship with customers through Facebook page allowed customers to show trust and brand recognition (Katona et al., 2011). The Facebook platform allows SMEs to engage with customers in twoway communication. This allowed SMEs to learn more about customers' behaviours, buying patterns, and product or service preferences.

Although Facebook enables SMEs to engage with customers more closely, it creates a hidden issue for SMEs as well. Due to electronic word-of-mouth (eWOM), customers possessed a strong influence to affect potential customers in the buying decision (Koh, $\mathrm{Hu}$, and Clemons, 2010). Traditional marketing does not leave any feedback, complaint, and comment from customers. Nonetheless, with social media as a major advertisement tool, the words can be easily spread negative feedback in the comment section (Culnan et al., 2010).

Facebook pages create an online platform for SMEs to engage customers directly. It has become one of the major platforms in building long-term relationships and attracting new customers through the recommendation from existing customers (Gajewski, 2013). By spending time on Facebook, more data are generated to learn and study the customers' behaviour and upheld its business value as well. As such, Facebook marketing enables potential customer engagement with SMEs.

\section{Discussion}

This paper identifies factors influencing SMEs to engage in Facebook online marketing in Malaysia. First, good branding builds long-term relationships with customers. High brand awareness correlates with high consumer participation and loyalty. In this way, strong brand familiarity builds consumer identification. Customers can recall a brand's opinion of an item, increasing brand identification and memory when shopping. Second, as one of the leading social media, Facebook has a large user base. Facebook's "like" function has amassed millions of admirers. SMEs may expand their consumer base by enlisting additional supporters of their firm and brand. Third, customers who connect with a brand are more likely to buy items or services online. This connection may develop into a strong online relationship. If the company values its consumers, it encourages them to be frequent and support its Facebook page. Finally, Facebook has improved marketing activity, but SMEs struggle to quantify the ROI of Facebook marketing. Typical marketing ROI measurements do not apply to Facebook marketing. Because the features of each social media site vary, the ROI calculation cannot be applied universally, and thus, it is necessary to identify its components.

\section{Conceptual Framework}

This study's conceptual framework (Figure 3 ) is based on the factors discussed earlier. The four factors consist of brand awareness, new customer base, cost-efficiency, and customer engagement which influence SMEs to engage in Facebook Marketing. 


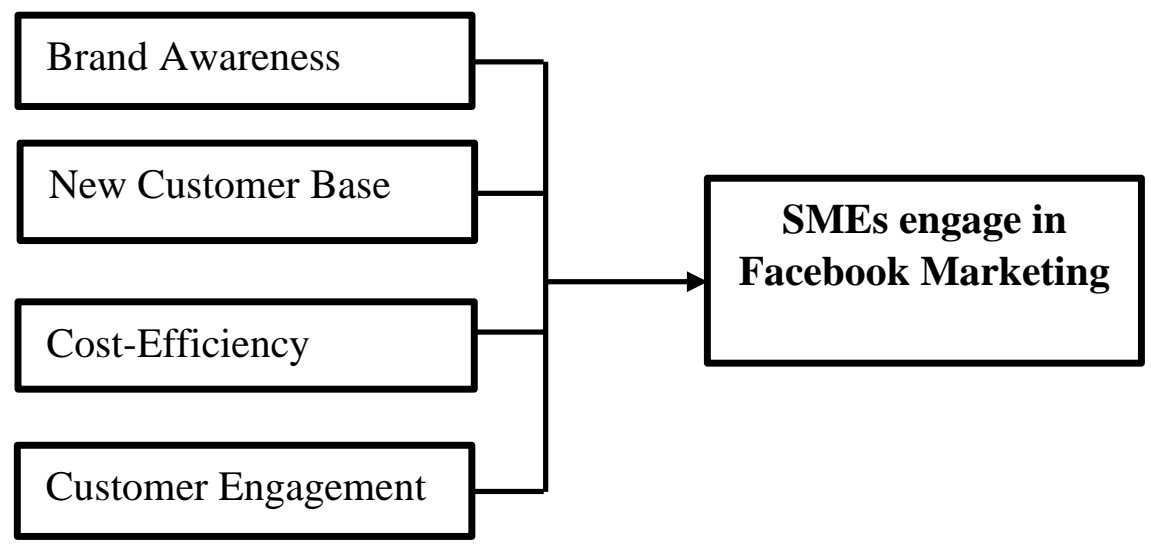

Figure 3: Factors that influence Malaysian SMEs to engage in Facebook Marketing

\section{Conclusion and Future Studies}

Past researchers have highlighted the need for more research on social media marketing especially on Facebook marketing among SMEs. This study proposes a conceptual framework on the factors influencing SMEs to engage in Facebook online marketing in Malaysia. The study further broadens the understanding of social media marketing and the contributing factors of Malaysian SMEs engaging in Facebook marketing. This study is in line with social media trends as a marketing tool for a business to enhance brand awareness, create a new customer base, increase cost-efficiency, and customer engagement. It also provides vital information to the policymakers, educators, and entrepreneurs to better understand the engagement of SMEs in social media marketing and ultimately help the SMEs increase their market presence and revenues.

Utilizing a qualitative approach, the study could be expanded into multiple-case studies with SMEs who already adopted Facebook marketing in their firms. The case study design could increase the understanding of the reasons relating to SMEs engaged with Facebook marketing. Semi-structured interviews can be developed and utilized during in-depth interviews with the SMEs. This is to ensure that the SMEs through their lead entrepreneurs give full information of their experience.

\section{References}

Banks, A., \& Haan, P. (2017). Facebook and branding of small to medium-sized enterprises. Association of Marketing Theory and Practice Proceedings 2017. 9. https://digitalcommons.georgiasouthern.edu/amtp-proceedings_2017/9

Behan, M. K. (2013). Efficacy of social media in participant perception of brand in small to medium size enterprises. (Order No. 3558933). (Doctoral Dissertation). Available from ProQuest Dissertations and Theses database. (No. 1352774106)

Bower, P. (2012). Forecasting new products in consumer oods. Journal Of Business Forecasting, 31(4), 4-30.

Brown-Peterson, A. J. (2017). Successful Facebook marketing strategies by Missouri small businesses: A qualitative case study. ProQuest LLC, (May), 145. https://doi.org/10.1111/exd.13500

Chen, J. (2019). What is Return on Investment (ROI). Retrieved from https://www.investopedia.com/terms/r/returnoninvestment.asp

Chin, C., Lu, H., \& Wu, C. (2015). Facebook users' motivation for clicking the "like" button. Social Behavior and Personality: An International Journal, 43(4), 579- 592. 
doi:10.2224/sbp.2015.43.4.579

Companies Commission of Malaysia (2020). Company and Business Registered Statistics for 2020. Retrieved from https://www.ssm.com.my/Pages/Publication/Statistics/Companies\%20and \%20Business\%20Registered/Company\%20and\%20Business\%20Registered\%20Statistic \%20for\%202020/Company-and-Business-Registered-Statistic-2020.aspx\#

Cox, S. L. (2012). Social media marketing in a small business: A case study. (Order No.530195, Purdue University). (Doctoral dissertation). Available from ProQuest Dissertations and Theses database. (No. 1239185181).

Culnan, M., McHugh, P., \& Zubillaga, J. (2010). How large U.S. companies can use Twitter and other social media to gain business value. MIS Quarterly Executive, 9(4), 243-259. Retrieved from http://misqe.org/ojs2/index.php/

Das, S. K., \& Sankar, G. (2016). Traditional marketing VS digital marketing: An analysis. International Journal of Commerce and Management Research, 2(8), 5-11.

Dehghani, M., \& Tumer, M. (2015). A research on effectiveness of Facebook advertising on enhancing purchase intention of consumers. Computers in Human Behavior, 49, 597600. doi:10.1016/j.chb.2015.03.051

Deighton J., \& Kornfeld, L. (2012). Economic value of the advertising-supported internet ecosystem. Interactive Advertising Bureau. Retrieved from http://www.iab.com/wpcontent/uploads/2015/07/iab_Report_September-24-2012_4clr_v1.pdf

Facebook. (2018). Company-info: Stats. Retrieved from https://newsroom.fb.com/companyinfo/

Farook, F. S., \& Abeysekara, N. (2015). Influence of social media marketing on performance. International Journal of Innovative Research \& Development, 5(12), 115-125.

Fisher, T. (2009). ROI in social media: A look at the arguments. Journal of Database Marketing \& Customer Strategy Management, 16(3), 189-195.

Gajewski, A. S. (2013). A qualitative study of how Facebook storefront retailers convert fans to buyers. Dissertation Abstracts International Section A: Humanities and Social Sciences, 74(6-A(E)), No-Specified. https://doi.org/UMI Number: 3553070

Gregori, A., \& Baltar, F. (2013). Ready to complete the survey on Facebook. International Journal Of Market Research, 55(1)131-148, doi: 10.2501/IJMR-2013-010

Haque, A., Momen, A., Sultana, S., \& Yasmin, F. (2013). Effectiveness of Facebook towards online brand awareness: A study on Malaysian Facebook users erspective. Australian Journal of Basic and Applied Sciences, 7(10), 197-203.

Hosford, C. (2011). Social marketing ROI: A work in progress. B to B. Retrieved from http://adage.com/article/btob/social-marketing-roi-a-work-progress/282279/

Kaplan, A. M., \& Haenlein, M. (2012). Social media: back to the roots and back to the future. Journal of Systems and Information Technology, 14, 101-104.

Katona, Z., Zubcsek, P., \& Sarvary, M. (2011). Network effects and personal influences: The diffusion of an online social network. Journal of Marketing Research, 48, 425-443. doi:10.1509/jmkr.48.3.425

Kim, M. K. (2010). The effectiveness of product conversations in social media: From an attribution theory perspective (Doctoral Dissertation). Available from ProQuest Dissertations and Theses database. (UMI No. 3433017).

Koh, N., Hu, N., \& Clemons, E. (2010). Do online reviews reflect a product's true perceived quality? An investigation of online movie reviews across cultures. Electronic Commerce Research and Applications, 9, 374-385. doi:10.1016/jeler- ap.2010.04.001 
Malaysia Communication and Multimedia Commission. (2018). Internet User Survey 2018. Retrieved from_https://www.mcmc.gov.my/skmmgovmy/media/General/pdf/InternetUsers-Survey-2018.pdf

Mabry, E., \& Porter, L. (2010). Movies and MySpace: The effectiveness of official websites versus online promotional contests. Journal of Interactive Advertising, 10(2), 1-15

Mickey, B. (2011). Social Media and Marketing a Major Topic of Discussion. Funworld, 27(1), 34-35.

Mital, M., \& Sarkar, S. (2011). Multihoming behavior of users in social networking websites: A theoretical model. Information Technology \& People, 24, 378-392. doi:10.1108/09593841111182250

Morch, A. (2011). Your social media product and service life cycle. Retrieved from https://aremorch.com/consulting/your-social-media-product-and-service-life-cycle/

Palmer, A., \& Koenig-Lewis, N. (2009). An experiential social network-based approach to direct marketing, International Journal of Direct Marketing, 3(3), 162-176.

Peaslee, J. (2015). Thrive analytics. Small businesses struggle to keep pace with digital marketing. Retrieved from http://www.thriveanalytics.com/blog/?p=420

Rios, R. E., \& Riquelme, H. E. (2010). Sources of brand equity for online companies. Journal of Research in Interactive Marketing. doi:10.1108/17505931011070587

Schmidt, S. M. P., \& Ralph, D. L. (2011). Social media: more available marketing tools. The Business Review, Cambridge, 18(2), 37-43. Retrieved from http://www.jaabc.com/

Sjoberg, A. (2017). Influencing brand awareness through social media title: Influencing brand awareness through social media case: BEdesign Oy in Facebook and Instagram Supervisor (Arcada). 1-82.

SME Corp Malaysia. (2013). SME definitions. Retrieved from http://www.smecorp.gov.my/index.php/en/policies/2015-12-21-09-09-49/smedefinition

Somera, L. P. (2014). Using social networks to build business connections: Engagement and interactivity on Guam's restaurants' Facebook pages. Entrepreneurial Executive, 19, 183-193. Retrieved from http://www.alliedacademies.org/entrepreneurial-executive/

Statista Research Department. (2021). Facebook: number of monthly active users worldwide 2008-2021. Retrieved from https://www.statista.com/statistics/264810/number-ofmonthly-active-facebook-users-worldwide/

Stelzner, M. A. (2013). Social media marketing report: How marketer are using social media to grow their business. Retrieved July 25, 2013 from

http://www.socialmediaexaminer.com/SocialMediaMarketingIndustryReport2 013.pdf

Terry, J., \& Savitz, E. (2011). Social commerce: Luring customers to your Facebook page. Forbes.Com. Retrieved from http://www.forbes.com/sites/ ciocentral/2011/07/08/social-commerce-luring-customers-to-your-facebook-page/

Wee, M., Yusrey, N., Sadik, M. Z., Razak, N. A., Marmaya, N. H., \& Yanto, H. (2020). Roles of Facebook usage among SMEs in Malaysia. International Journal Academic Research in Business and Social Sciences, 10(3), 723-732. 